\title{
EL EMPLEO DE LAS NUEVAS NORMAS ORTOTIPOGRÁFICAS DE LA LENGUA ESPAÑOLA EN PUBLICACIONES CIENTÍFICAS MÉDICAS
}

\author{
USE OF SPANISH NEW SPELLING AND TYPOGRAPHIC RULES IN MEDICAL SCIEN- \\ TIFIC PUBLICATIONS
}

Manuel José AguiLAR RuIZ

Tecnolingüística S. L.

RESUMEN:

El objetivo del presente artículo es analizar el grado de cumplimiento de la normativa ortotipográfica académica recogida en la Ortografía de la lengua española (OLE, 2012) que realizan algunas publicaciones periódicas de carácter científico-técnico (y, en concreto, del ámbito médico-quirúrgico). Para ello, comentamos los errores e incorrecciones más recurrentes de un corpus de publicaciones científicas del presente año.

PALABRAS ClAVE: Ortografía (2012), nuevas normas académicas, innovaciones ortotipográficas, revistas médicas.

\section{ABSTRACT:}

This paper aims to analyze how the spelling and typographic rules described in Ortografía de la lengua española (OLE, 2012) are followed in some scientific-technical periodical publications (and, specifically, the medical-surgical). For this purpose, the most frequent errors from a corpus of scientific publications will be discussed.

KEY WORDS: Orthography (2010), new Royal Spanish Academy rules, orthotipographic innovations, medical reviews. 


\section{INTRODUCCIÓN}

La publicación en 2010 de la nueva Ortografía ${ }^{1}$ por parte de la Real Academia Española (RAE) y de la Asociación de Academias de la Lengua Española (ASALE) ha supuesto, aparte de la normativización de determinadas innovaciones ortográficas, un serio intento académico de unificación normativa ortotipográfica para la labor de edición y publicación de documentos, unificación que ya se venía ofreciendo en diversos manuales $^{2}$ y el Diccionario Panhispánico de Dudas (2005). En el presente artículo pretendemos analizar el cumplimiento de dicha normativa que realizan algunas publicaciones periódicas de carácter científico-técnico y, en concreto, de un ámbito específico que nos parece fundamental para la transmisión del conocimiento humano, como son las publicaciones médicas. Para ello, hemos realizado la recopilación y consulta a un extenso corpus - consideramos que suficientemente representativo- de casi una treintena de revistas de cirugía, medicina y biomedicina ${ }^{3}$ publicadas a lo largo de 2012 (centrándonos en la mayor parte en los números comprendidos entre los meses de abril y agosto, con excepciones).

La diversidad de nuestro corpus viene representada por la selección de publicaciones del campo médico (cardiología, nefrología, oftalmología, etc.) y quirúrgico (cirugía general y cirugía plástica) exclusivamente, tanto impresas (Cirugía Española) como on-line (gran parte de ellas facilitadas por las bases búsqueda de Elsevier, Scielo y Medigraphic), especializadas (la gran mayoría) y divulgativas (Revista Natural y Ciencia y Desarrollo), españolas (Casos Clínicos de Cirugía General, Cirugía Española, Revista Clínica de Medicina Familiar, Revista Española de Cardiología, etc.) e hispanoamericanas (Archivos de Cardiología de México, Cirugía Plástica Ibero-Latinoamericana, Revista Argentina de Cirugía, Revista Iberoamericana de Micología, Revista Médica de Costa Rica y

\footnotetext{
${ }^{1}$ Ortografía de la lengua española; en adelante, OLE (2010).

${ }^{2}$ Como, por ejemplo, el Diccionario de ortografía técnica (1999), la Ortografía y ortotipografía del español actual (2008a) o el Manual de estilo de la lengua española (2008b), de Martínez de Sousa.

3 Dicho corpus queda integrado por las siguientes publicaciones: Angiología, Archivos de Bronconeumología, Archivos de Cardiología de México, Archivos de la Sociedad Española de Oftalmología, Avances en Odontoestomatología, Casos Clínicos de Cirugía General, Ciencia y Desarrollo, Cirugía Española, Cirugía Plástica Ibero-Latinoamericana, Clínica e Investigación en Arterioesclerosis, Cuadernos de Medicina Forense, Emergencias, Enfermería Nefrológica, Hipertensión y Riesgo Vascular, Revista Argentina de Cirugía, Revista Clínica de Medicina Familiar, Revista Clínica Española, Revista Cubana de oftalmología, Revista Chilena de Radiología, Casos clínicos de la Asociación Argentina de Cirugía (web), Revista de la Sociedad Española del Dolor, Revista Española de Cardiología, Revista Española de Enfermedades Digestivas, Revista Española de Salud Pública, Revista Iberoamericana de Micología, Revista Médica de Costa Rica y Centroamérica, Revista Natural y Revista Venezolana de Cirugía, a las que se le suma el manual quirúrgico Eventraciones. Otras hernias de pared y cavidad abdominal (2012).
} 
Centroamérica, Revista Venezolana de Cirugía, etc.), a lo que sumamos el manual quirúrgico Eventraciones. Otras hernias de pared y cavidad abdominal, publicado en $2012^{4}$. Nos basamos en nuestra experiencia en labores de corrección y edición de dicho manual, gracias a lo cual advertimos una serie de errores ortográficos y ortotipográficos recurrentes que se suelen repetir en este tipo de publicaciones ${ }^{5}$.

Así pues, partiendo siempre de la normativa académica, observaremos determinados usos ortotipográficos impropios y erróneos -forzosamente de manera muy reducida, dadas las características del presente trabajo- que suelen darse en este tipo de publicaciones, relativos a algunas de las fórmulas de expresión que conforman las características de la comunicación científica, como son la creación léxica mediante prefijación (uno de los procedimientos más rentables de la creación de términos en el lenguaje científico ${ }^{6}$ ), y el empleo de abreviaturas, símbolos y siglas, además de breves puntualizaciones sobre el uso de las mayúsculas y de la letra cursiva. En el artículo, los ejemplos se citarán siempre mediante una clave identificativa (que no es más que la sigla del nombre de cada trabajo en cuestión); al final se facilita una lista que ordena alfabéticamente las distintas claves (que hemos llamado «Publicaciones científicas citadas»), para obtener así su completa referencia bibliográfica.

\section{ERRORES RELATIVOS A LA PREFIJACIÓN}

Según la normativa académica (OLE, 2010: 531-2), un prefijo se ha de escribir siempre unido a la palabra a la que prefija, nunca separado de ella (ni por un espacio en blanco ni por un guion), sino «soldado gráficamente a la base a la que afecta» (OLE, 2010: 420). Como hemos podido comprobar mediante nuestro trabajo con el corpus, el incumplimiento de la norma anterior en los textos científico-técnicos del ámbito médico parece un hábito muy recurrente, debido a la influencia del inglés, y podemos observar usos incorrectos como los de *anti-microbiano, *sub-basal, *auto-rechazo, etc. en los ejemplos siguientes:

1. El metronidazol es un agente *anti-microbiano utilizado para el manejo de infecciones por protozoarios como la tricominiasis e infecciones anaeróbicas (VB: 185).

\footnotetext{
${ }^{4}$ Carbonell, Fernando y Alfredo Moreno, coords. (2012): Eventraciones. Otras hernias de pared y cavidad abdominal, Valencia, Ethicon.

${ }^{5}$ Hemos de señalar que el resultado final de nuestra labor de corrección y edición del manual obtuvo una mención distintiva del Instituto Cervantes, en calidad de «Fomento del español en la ciencia».

${ }^{6}$ Cfr. Martín (2004: 58 y ss.).
} 
2. El grosor medio de cada fibra *sub-basal es entre 2 y $4 \mathrm{~mm}$, y el de las fibras subepiteliales entre 3 y $7 \mathrm{~mm}$ (MCOS [en línea]).

3. [pacientes] con alta dosis de autoexigencia, baja autoestima, *auto-rechazo y falta de aceptación en edad joven por problemas de sobrepeso (MTCTCA [en línea]).

4. La HDF [hemodiafiltración] *post-dilucional parece ser una mejor alternativa respecto a la *pre-dilucional en relación a los parámetros estudiados siempre que no se tenga en cuenta la problemática de los accesos vasculares (HLPFP: 112).

5. Hubo una muerte *intra-quirófano, inestable, y durante los primeros 30 días fallecieron otros 4 pacientes (SCEUCTFA: 199).

6. El tratamiento no está basado en un criterio unánime, debiendo tenerse en cuenta diversos factores: (...) etapa evolutiva (*pre-necrótica, ulcerosa) y la aparición de complicaciones ( $L C: 75)$.

Por lo tanto, solo se considerarán correctos empleos como, por ejemplo, preoperatorio, reintervenciones y subcostal, en los fragmentos siguientes:

7. De igual manera, se evaluaron los RFA [reactantes de fase aguda] en el preoperatorio y a lo largo del seguimiento (RRQAI: 208).

8. Un paciente $(2,6 \%)$ falleció en el postoperatorio inmediato y se realizaron 3 reintervenciones por sangrado (7,8\%) (RRQAI: 206).

9. En nuestra experiencia, en la cirugía subcostal las alteraciones respiratorias presentan una mínima incidencia (FRPETI: 798).

Además, la norma anterior se observará incluso cuando la prefijación cause el encuentro de dos vocales idénticas (OLE, 2010: 164-5):

10. Como principales conclusiones, podemos destacar que los niveles de presión intraabdominal de nuestros pacientes son algo más elevados que en otras series. ${ }^{7}$ (RPIDPHF: 95).

11. Las pacientes con preeclampsia leve se hospitalizan para confirmar el diagnóstico y hacer estudios adicionales (PREEC: 195).

${ }^{7}$ Cfr. la traducción al inglés de este mismo texto, en la misma página, donde se presenta el prefijo unido mediante guion a su base léxica: «As the principal conclusions, we would stress that the intraabdominal pressure levels in our patients were rather higher than in other series».

NORMAS. REVISTA DE ESTUDIOS LINGÜÍSTICOS HISPÁNICOS, NÚMERO 2 (AÑO 2012):

http://www.uv.es/normas 
12. El propósito de este estudio fue evaluar la asociación de los polimorfismos del gen MHC2TA y el riesgo de desarrollar reestenosis, después del implante de stent coronario en un grupo de pacientes mexicanos (MHC2TA: 209).

13. La magnetoterapia presenta excelentes resultados analgésicos, antiinflamatorios y estimulante de la formación del callo óseo (UCMCC: 123).

Serían, pues, expresiones incorrectas las que aparecen en los siguientes casos:

14. (...) habiéndose demostrado su funcionalidad como genes supresores de tumores o como *proto-oncogenes en la carcinogénesis (EYCC: 281).

15. Cuatro [las fístulas aortoentéricas secundarias] se trataron con bypass *extraanatómico, 3 [fueron] inestables. ${ }^{8}$ Serie de casos (SCEUCTFA: 199).

Otro problema recurrente en las publicaciones médicas consultadas consiste en la necesidad de coordinar varios prefijos ante una misma palabra. En este caso, la Ortografía prescribe que los prefijos separados se escriban con un guion pospuesto, con lo que se indicará que no se tratan de de palabras autónomas, sino de segmentos afijos vinculados a la base léxica a la que modifican (OLE, 2010: 543-544). Por lo tanto, no sería correcto tratarlos como palabras autónomas, escritos separadamente de su base léxica (ejemplo 16), ni escribir con guion el prefijo más cercano a esta (17):

16. Tabla 1. Cambios del IMC $\left(\mathrm{kg} / \mathrm{m}^{2}\right) *$ pre y *post operatorio.

Tabla 2. Porcentaje del vaciamiento (\%) gástrico *pre y *pos operatorio en treinta (30) minutos.

Tabla 3. Promedio de volumen gástrico (ml) *pre y posoperatorio (GVLEVG: 39).

17. El objetivo de este estudio fue comparar distintos parámetros dialíticos y hemodinámicos entre los modos de HDF *pre y post-dilucional (HLPFP: 110).

En estos casos, pues, la opción correcta sería la solución que se muestra en el ejemplo 18:

18. En el 3,6\% de los casos se utilizó un mini- o microinstrumento $(\leq 3 \mathrm{~mm})$ como sistema de ayuda para finalizar el procedimiento (CLIUARN: 302).

\footnotetext{
${ }^{8} \mathrm{Cfr}$. el original, en inglés y en la misma página, donde se observa el mismo caso que la nota anterior: «Four were treated with extra-anatomical bypass».
}

NORMAS. REVISTA DE ESTUDIOS LINGÜÍSTICOS HISPÁNICOS, NÚMERO 2 (AÑO 2012):

http://www.uv.es/normas 
Por último, observamos ciertas dudas a la hora de escribir con o sin guion el adverbio no antepuesto a sustantivos (generalmente abstractos), con un uso semejante a un prefijo privativo. La normativa académica establece que en estos casos el adverbio no debe escribirse siempre separado de la palabra a la que antecede y, además, sin guiones (OLE, 2010: 542):

19. Se presenta un caso de enfermedad de Castleman multicéntrica con múltiples ganglios linfáticos que muestran una intensa captación de FDG, imitando el linfoma *no-Hodgkin. (...) La ${ }^{18} \mathrm{~F}$ FDG-PET mostró múltiples áreas de aumento de captación en ganglios linfáticos cervicaleses, mediastínicos, hiliares, retroperitoneales e inguinales, sugiriendo una enfermedad generalizada del sistema linfático, como el linfoma *no-Hodgkin (FDGPETTAC: 142).

Esta escritura del adverbio no con guion es un anglicismo ortográfico, debido al fenómeno del «mimetismo ortográfico» ${ }^{9}$ de la tradición tipográfica anglosajona, hecho habitual en este tipo de trabajos científicos -como comprobaremos a lo largo del presente trabajo- por el peso que tienen dichas publicaciones en inglés. Así, si observamos el texto original del fragmento anterior (ya que se trata del resumen en español de un artículo redactado en inglés), encontramos este hábito de escritura con guion:

20. We report a case of a multicentric form of Castleman's disease with multiple lymph nodes showing intense FDG uptake on whole body scan mimicking non-Hodgkin's lymphoma. (...) ${ }^{18}$ F-FDG/PET demonstrated multiple areas of increased uptake in cervical, mediastinal, hilar, retroperitoneal and groin lymph nodes, suggesting a generalized disease of the lymphatic system including non-Hodgkin's lymphoma.

Así pues, el empleo normativo sería, como hemos comentado, la escritura sin guion, como la secuencia no inmunodeprimido del siguiente ejemplo:

21. No está bien definida la actitud terapéutica ante una posible aspergilosis pulmonar en un paciente no inmunodeprimido con insuficiencia respiratoria (APPCNI: 91).

\footnotetext{
${ }^{9}$ Tal y como denominó a este fenómeno Rosenblat (apud Martínez de Sousa, 2008b: 152).
} 


\section{INCORRECCIONES RELATIVAS A LAS ABREVIATURAS}

En lo que respecta a usos incorrectos de las abreviaturas, los casos más llamativos que hemos encontrado y que querríamos destacar aquí son los referentes a la supresión de su punto abreviativo, a la formación de su plural y al empleo de abreviaturas procedentes de otras lenguas.

Normalmente, en las normas de publicación de las revistas consultadas se suele aconsejar el empleo únicamente de las abreviaturas estándar, y que se evite la aparición de estas tanto en el título como en el resumen.

Como especifica la Ortografía (oLE, 2010: 568 y ss.), la expresión de cada abreviatura en español viene dada por la tradición, que es lo que origina su configuración especial. Por ejemplo, para las abreviaturas de fórmulas de tratamiento y de atribución profesional -frecuentes en este tipo de escritos, como Dr. (doctor), Dir. (director) o Prof. (profesor) - se prescribe la obligatoriedad de que se escriban con mayúscula inicial, incluso cuando en el contexto discursivo en el que aparecen no deberían ir así ${ }^{10}$.

Así, como hemos anticipado, el primer problema ortográfico relativo a las abreviaturas que comentaremos consiste en la supresión del punto con el que se cierra toda abreviatura en español, llamado «punto abreviativo». La omisión de este constituye un grave error ortográfico:

22. Así Levinson y *cols, afirman que la información asequible y detallada es un aspecto importante en esta relación (SPUD: 103).

El plural de una abreviatura se forma añadiendo una $s$ antes del punto abreviativo (OLE, 2010: 573), como Figs. (plural de Fig., abreviatura de 'Figura') o y cols. ('y colaboradores', que solo presenta forma plural ${ }^{11}$ ) en los ejemplos 23,24 y 25 :

23. Las radiografías de cráneo y tórax fueron realizados y no mostró cambios (Figs. 5 y 6) (FMPPI: 121).

24. En el estudio multicéntrico de Pawlick y cols. la media de ganglios extraídos con o sin resección ductal fue de 3 (CBT2P: 19).

25. Tham y cols. observaron una dosis máxima sobre el feto de $3 \mathrm{mGy}$-hasta 3 minutos de fluoroscopia- y Kahaleh y cols. de $1,8 \mathrm{mGy}$ en sus respetivos grupos de pacientes (CPREDE: 56).

\footnotetext{
${ }^{10}$ Cfr., sin embargo, Martínez de Sousa (2008a: 193).

${ }^{11}$ Cfr. Aleza (2011: 78).
} 
Así pues, siguiendo la norma anterior, la escritura de las abreviaturas que aparecen en los casos 22 (que se ha ofrecido supra) y 26 sería incorrecta: en el primero, por la omisión del punto abreviativo, y en el segundo, por la omisión de la $s$ que marcaría el plural. El error suele ser frecuente cuando se ofrece, en la citación bibliográfica (tanto en el texto como en la bibliografía final), los colaboradores ( $y$ cols.) del autor de un trabajo:

26. El método utilizado fue similar al realizado por Figueredo y *col. (UVIFICB: 20).

Sin embargo, para la formación del plural de las abreviaturas obtenidas por truncamiento extremo, se dobla la letra conservada, separada siempre por un espacio en blanco (OLE, 2010: 573; Aleza, 2011: 79), por lo que el siguiente ejemplo se consideraría erróneo:

27. [El nuevo programa] ha originado dos resoluciones de gran trascendencia, una sobre acreditación de las Unidades Docentes (*UUDD) (...) y otra sobre la incorporación de una rotación en atención primaria en los programas formativos de 18 especialidades médicas (PRMFCPFE: 18).

El caso más llamativo lo constituyen las diferentes soluciones erróneas para nombrar a los Estados Unidos ${ }^{12}$ : frente a la expresión correcta (EE. $U U$., del ejemplo 28), encontramos casos sin punto abreviativo (29) ni espacio en blanco (30 y 31):

28. Los análisis estadísticos se realizaron utilizando el software SAS versión 9.2 (SAS Institute Inc., Cary, NA, EE. UU.) (ALFSEV: 176).

29. Las primeras vacunas antigripales comercializadas fueron aprobadas en *EEUU en 1945 y dos años después se reconoció que los cambios antigénicos en la hemaglutinina de los virus gripales podía alterar la eficacia de la vacuna (VNRAVGPE: 242).

30. En *EE.UU., considerada una población total estimada de perros, solo se relacionan con muertes humanas un 0,00000003\% de los perros (AMPRRMA: 71).

31. Si tenemos en cuenta que, solamente en *EE.UU. y cada año, se denuncian 14.000 casos por sus efectos secundarios, multipliquemos esa cifra por el resto de la población mundial y quizá comencemos a preocuparnos (VINIP [en línea]).

\footnotetext{
${ }^{12}$ Cfr. Martínez de Sousa (2008a: 199).
} 
Por otro lado, en las iniciales de los nombres propios no debe suprimirse el punto abreviativo (OLE, 2010: 571), ni tampoco el espacio en blanco entre las iniciales de los nombres propios compuestos ${ }^{13}$, como en los nombres que firman los siguientes artículos que nos sirven de ejemplo:

32. Romero Romero *GE, Ramos Manotas *J, Díaz Caballero *A (CIVMA: 125).

33. *J.R. Domínguez Vicent, *M.S. Díaz Gómez (RIMEPSED: 8).

Tampoco se ha de suprimir el punto abreviativo en las abreviaturas de los nombres propios con letras voladas (cfr. Aleza, 2011: 80):

34. José * $\mathrm{M}^{\mathrm{a}}$ Alonso Gordo (LC: 73).

Siguiendo la normativa académica $(O L E, 2010: 570)^{14}$, tampoco en S. A. (sociedad anónima) y S. L. (sociedad limitada) deberían suprimirse sus respectivos puntos abreviativos y espacios en blanco, aunque ambas abreviaturas son también realizables como siglas (SA y SL, respectivamente):

35. [la vacuna] Chiromas ${ }^{\circledR}$ de Laboratorio Novartis Vaccines and Diagnostics SL (VNRAVGPE: 244).

Por último, las abreviaturas originarias de otras lenguas se marcan en cursiva, por lo que la abreviatura et al. (et alii, 'y otros'), procedente del latín, debería haberse marcado con letra cursiva en el siguiente texto:

36. En 1972, Walker *et al. describieron los AIAA y los definieron como una entidad clínica y fisiopatológica distinta al AAA aterosclerótico (RRQAI: 210).

\section{INCORRECCIONES RELATIVAS A SIGLAS Y ACRÓNIMOS}

A diferencia de las abreviaturas, las siglas y acrónimos no se marcan con punto abreviativo (OLE, 2010: 583).

\footnotetext{
${ }^{13}$ Espacio en blanco que puede venir representado por un espacio fino (OLE, 2010: 576).

${ }^{14}$ Cfr. también Aleza (2011: 80).
} 
37. En 1984, la profesora Zoila Pérez Rodríguez logra incorporar al servicio del Sanatorio Topes de Collante varios equipos de campo electromagnético local que procedían de la antigua URSS (UCMCC: 119).

38. En la Red Española de Investigación de la Infección en el Trasplante (RESITRA), la incidencia de enfermedad invasiva con profilaxis fue del 3,9\% (CIPSRU: 99).

Es recomendable que, cuando aparezcan una sigla o un acrónimo por primera vez, estos han de ir acompañados por el término completo al que corresponde, para facilitar al lector su correcta interpretación (OLE, 2010: 578):

39. En diálisis peritoneal (DP) la prevalencia de malnutrición parece ser elevada oscilando entre el 18-56\% según diferentes estudios.

Existen numerosos factores implicados en la malnutrición en DP como la escasa ingesta oral favorecida por múltiples factores como la edad, la pérdida de función renal residual, la diálisis inadecuada (...) (EGSEMI: 88).

40.La medición automática de la presión sanguínea en consulta (MAPSC) presenta importantes ventajas sobre la medición manual de la presión arterial en consulta (MMPAC). La MAPSC requiere el uso de un esfigmomanómetro (...) (NCMPAC: 63).

En plural, siglas y acrónimos -al igual que los símbolos- permanecen invariables. Su plural, pues, no se marca ni con una $S$ ni con el calco inglés de 's (OLE, 2010: 583); por lo tanto, frente a la expresión errónea de 41, podemos observar la corrección de 42 y 43.

41. En los últimos años se ha incrementado el esfuerzo de los investigadores en lo referente al desarrollo y perfeccionamiento de instrumentos de evaluación que permitan al médico de *APS identificar los distintos trastornos mentales (EIPADAP: 41).

42. [Los resultados] reflejan que la asociación de analgésicos más utilizada para el tratamiento del dolor era la formada por AINE [antiinflamatorios no esteroideos] en combinación con opiodes menores (RCEHO: 130).

43. Las FAE [fístulas aortoentéricas] secundarias aparecieron tras una media de tiempo de 85,8 meses (SCEUCTFA: 199).

Algunos acrónimos muy comunes (como TAC, de tomografía axial computarizada, o LASER, del inglés light amplification by stimulated emission of radiation) acaban lexicalizándose, y pasan a convertirse «en palabras a todos los efectos» (OLE, 2010: 584; 578-9), del tipo tac o láser (siguiendo los ejemplos 
anteriores). Dicho proceso de lexicalización, tal y como contempla la Ortografía ${ }^{15}$, es gradual (depende en gran medida de la condición como siglas o acrónimos con las que las considere el hablante), por lo que es frecuente que durante largo tiempo conviva su documentación con grafías en mayúsculas o en minúsculas, dependiendo de su concepción como siglas/acrónimos o como palabras independientes, respectivamente. Así, en los ejemplos 44 y 45 encontramos el uso de TAC como acrónimo, aunque podría haberse empleado la voz tac, como se recoge en el DRAE o en OLE (2010: 584):

44. Los abscesos pequeños (menores de $2 \mathrm{~cm}$ de diámetro) pueden tratarse con antibióticos parenterales, los más grandes se tratan mejor mediante drenaje percutáneo guiado con TAC (EDCG: 176).

45. El estudio radiológico es el estudio inicial y en gran número de ocasiones el único estudio por imagen dada la escasa capacidad de modificación de las pautas de tratamiento por los hallazgos de TAC o de la RMN (UCMCC: 118).

En el siguiente ejemplo (46), sin embargo, se puede observar que la primera mención del vocablo láser aparece en mayúscula, contemplado, pues, como acrónimo (con toda seguridad para explicar a continuación la expresión inglesa que lo originó), mientras que en sus restantes apariciones en el texto el vocablo se ofrece ya lexicalizado ${ }^{16}$ :

46. LASER es la sigla de la expresión en inglés, light amplification by stimulated emission of radiation, que significa amplificación de luz por emisión estimulada de radiación.

El láser de $\mathrm{CO}_{2}$ marca NIDEK es un equipo de moderna tecnología de 10,6 $\mu \mathrm{m}$ de longitud de onda (CCPCCO2 [EN LÍNEA]).

\section{INCORRECCIONES RELATIVAS A LOS SÍMBOLOS}

Por lo que respecta al correcto empleo de los símbolos en el ámbito de la comunicación médica, hemos encontrado en nuestro corpus múltiples errores, de los que señalaremos los que han sido más frecuentes.

\footnotetext{
${ }^{15}$ En $O L E$ (2010: 584).

${ }^{16}$ Obsérvese, además, que en su primera mención (como acrónimo), LASER aparece sin acentuar, siguiendo la norma de que las siglas escritas enteramente en mayúsculas no portan nunca acentuación gráfica, al contrario los acrónimos ya lexicalizados, como láser, convertido ya en nombre común que se somete a las normas de acentuación gráfica del español (OLE, 2010: 584).
} 
En primer lugar, la configuración gráfica de cada símbolo viene dada por la tradición y por el consenso internacional ${ }^{17}$ (por ejemplo, por entidades de normalización como la ISO, International Organization for Standardization); por tanto, han de evitarse, tal y como insiste la normativa académica (OLE, 2010: 713-4), incorrecciones como las que se recogen en los ejemplos 47, 48 y 49, donde aparecen los erróneos *mt por $m$ (metro), $* h r$ por $h$ (hora), y $* g r$ por $g$ (gramo):

47. Los pacientes con edad mayor a 60 años, IMC menor a 35 ó mayor a $50 \mathrm{~kg} / * \mathrm{mt}^{2}(\ldots)$ (MEPSGVL: 43).

48. Proteinuria mayor o igual a $300 \mathrm{mg}$ pero menos de $5 \mathrm{~g}$ en una colección de orina de $24 * \mathrm{hr}($ PREEC: 195).

49. Proteinuria de $5 *$ gr en orina de 24 horas o su equivalente de 3 (PREEC: 195).

Además, al contrario que las abreviaturas, los símbolos no portan nunca punto abreviativo (OLE, 2010: 589). Los más proclives a sufrir este error son los símbolos alfabetizables (esto es, los formados por letras; cfr. OLE, 2010: 719), sobre todo los que simbolizan determinadas unidades de medida espacial (como $* \mathrm{~cm}$. en lugar de $\mathrm{cm}$ o $* m$. por $m$ ), de peso $(* g$. en vez de $g$ ) o de medición cronológica $(* h$. en lugar de $h)$ entre otras, tal y como testifican las siguientes documentaciones:

50. La presión intraabdominal final es la media entre las mediciones realizadas durante la inspiración y la espiración, se expresa en * $\mathrm{cm}$. de $\mathrm{H}_{2} \mathrm{O}$ (RPIDPHF: 94).

51. Cuando hablamos de los esquemas de administración oral, debemos saber que estos comprenden: uno de dosis única de $* 2 \mathrm{~g}$. otro de $2 \mathrm{~g}$ por día por dos días y $500 \mathrm{mg}$ cada 12 horas por siete días (VB: 185).

En nuestro corpus, destaca la profusión de símbolos en el texto en lugar del desarrollo como palabra de su significante, es decir, «como equivalentes de la palabra cuyo concepto representan» (OLE, 2010: 590). Este hábito, que resulta tan apropiado para los elementos paratextuales que suelen acompañar a los textos científico-técnicos (como tablas y gráficas), tendría que evitarse, sin embargo, en el discurso, por lo que habría que reducirse su uso a contextos muy limitados, como los citados anteriormente. Así por ejemplo, en el siguiente fragmento (el núm. 52), resulta incorrecta la aparición

\footnotetext{
${ }^{17}$ Cfr. OLE (2010: 586-7).
} 
de los símbolos del magnesio y del calcio en el texto ( $\mathrm{Mg}$ y $\mathrm{Ca}$, respectivamente), ya que se debería haber optado por el desarrollo de estos como vocablo ${ }^{18}$ :

52. La asociación de sulfato de magnesio con antagonistas del calcio debe evitarse, ya que estos últimos potencian los efectos tóxicos del $* \mathrm{Mg}$. Por otro lado, la aparición de toxicidad por magnesio se debe antagonizar con $1 \mathrm{~g}$ de gluconato de $* \mathrm{Ca}$ intravenoso (PREEC: 196).

El tipo de error anterior es más frecuente cuando se aparecen en el discurso símbolos matemáticos no alfabetizables, como mayor que (>), menor que (く), más menos $( \pm)$ mayor o igual que $(\geq)$, etc., cuya profusión, aunque parezca agilizar la lectura del texto, continúa siendo un uso incorrecto, ya que la aparición de dichos símbolos debería limitarse a tablas, gráficas y elementos similares ${ }^{19}$ :

53. En los niños $*<2$ años es más frecuente observar rechazo del alimento y retraso del crecimiento, mientras que los de 3-12 años suelen presentar vómitos, regurgitación, náuseas y dolor torácico. En los *>12 años la disfagia y la impactación de alimentos son las manifestaciones más habituales, como en el caso descrito (DAMEE: 55).

54. Se incluyeron 24 pacientes con FEVI $*<40 \%$, a quienes se les realizó cirugía de revascularización (TCCI: 224).

55. El nivel de significación se asumió cuando $\mathrm{p} *<0,05$ (VMNOPA: 350).

56. Se incluyó a aquellos pacientes * $\geq 65$ años que ingresaron de forma transitoria en convalecencia y/o larga estancia desde el 1 de enero de 2009 al 31 de diciembre de 2010 (FRECPAICS: 70).

57. Los tres métodos de medición automática de la PA definen la hipertensión como una presión arterial $* \geq 135 / 85 \mathrm{mmHg}$ (NCMPAC: 63 ).

Este hábito de ofrecer el símbolo en lugar del concepto tal vez se deba-además de a la agilidad que dicho uso confiere a la lectura, como hemos comentado- a la influencia de textos en inglés, pues en diversas ocasiones encontramos las traducciones inglesas del resumen -cuando no del escrito original, en inglés- expresadas con las mismas fórmulas. Así, en el siguiente ejemplo 58, tomado del resumen de un trabajo, podemos observar el error antes comentado, y, a continuación, en el 59, vemos que su traducción inglesa, en la misma página, ofrece la misma solución:

${ }^{18}$ Tal y como ocurre, por cierto, con la primera aparición discursiva de cada uno de estos elementos químicos en el fragmento.

${ }^{19}$ Obsérvese, además, que la mayoría de los ejemplos seleccionados (54, 55, 56 y 57) incurren en el error de separar con un espacio en blanco al operador matemático de la cifra a la que acompaña.

NORMAS. REVISTA DE ESTUDIOS LINGÜÍSTICOS HISPÁNICOS, NÚMERO 2 (AÑO 2012):

http://www.uv.es/normas

(ISSN 2174-7245) 
58. Los enfermos con presión intrabdominal $*>20 \mathrm{~cm}$. [sic] $\mathrm{H} 2 \mathrm{O}$ [sic] tenían más porcentaje de hernias (RPIDPHF: 94).

59. Patients with an intra-abdominal pressure of $>20 \mathrm{~cm} \mathrm{H2O}$ had a higher percentage of hernias (RPIDPHF: 94).

También habría que evitarse el hecho de ofrecer en el mismo texto las dos soluciones distintas (tanto símbolo como vocablo equivalente), siendo siempre de preferencia esta segunda opción, la de la palabra completa en lugar de su símbolo correspondiente (esto es, gramo en lugar de $* g$ y porcentaje en lugar de $* \%$, centrándonos en los casos siguientes):

60. (...) existe la opción de utilizar dosis única de $1 * \mathrm{~g}$, en vez de la acostumbrada dosis de 2 gramos en dosis única (VB: 186).

61. Considerando que el volumen inicial es el $100 \%$ de la capacidad gástrica, se determina el $* \%$ de vaciamiento mediante la diferencia del porcentaje de volumen obtenido a los 30 minutos con respecto al inicial (100\%) (GVLEVG: 38).

Además, debido a que cada símbolo es una expresión gráfica invariable, la forma única de cada uno de ellos servirá para expresar tanto el singular como el plural (OLE, 2010: 589). Es por ello por lo que en el ejemplo 62 hubiera sido incorrecto el intento de pluralizar el símbolo de horas $(h)$ en $* h s$, por más que se emplee en un contexto plural ${ }^{20}$ :

62. Se administró anidulafungina a una dosis de carga de $200 \mathrm{mg}$ i.v. cada 24 h y una dosis de mantenimiento de $100 \mathrm{mg}$ i.v. cada $24 \mathrm{~h}$. A las 36 horas del inicio de este tratamiento, el paciente presentó descenso de la curva térmica y disminución de los requerimientos de aminas vasoactivas (CIPCQ: 94).

Por otro lado, los símbolos han de escribirse pospuestos a la cifra que los cuantifica y separados de ella por un espacio (OLE, 2010: 590):

63. Utilizando un trócar traslúcido de $* 12 \mathrm{~mm}$, para cerrar el neumoperitoneo con $\mathrm{CO}^{2}$ [sic] a 15 mm Hg (GVLEVG: 39).

${ }^{20}$ No obstante, sí se recomendaría mantener cierta coherencia y, si se ha optado por emplear el símbolo $h$ en lugar de la palabra completa -debido a las peculiaridades lingüísticas del tipo de texto y por razones de agilizar la lectura-, sería aconsejable que este uso se mantuviera a lo largo de todo el documento. Sin embargo, como se puede observar en el fragmento, la aparición del símbolo $h$ alterna con la palabra completa.

NORMAS. REVISTA DE ESTUDIOS LINGÜÍSTICOS HISPÁNICOS, NÚMERO 2 (AÑO 2012):

http://www.uv.es/normas 
La normativa académica (OLE, 2010: 590) observa, no obstante, dos excepciones a la norma anterior: la primera, los números y símbolos volados (como los grados de temperatura, los minutos y segundos de los ángulos sexagesimales o las cifras en superíndice), que se deben escribir pegados a la cifra a la que acompañan, como se ejemplifica en los textos siguientes, referidos a los tres casos anteriores:

64. [al paciente] le aparece una ulceración con escara en dicha zona, aumento del dolor local, fiebre de $38^{\circ}$ y malestar general, acudiendo al Servicio de Urgencias en dos ocasiones ( $L C: 74)$.

65. Sin embargo, en los casos de cirugía de órgano sólido y bariátrica, existió una tendencia hacia el uso de laparoscopios de $10 \mathrm{~mm}$ y $30^{\circ}$ (CLIUARN: 303).

66. Este ángulo en reposo mide $108-127^{\circ}$ y sufre una variación de $15-20^{\circ}$ durante la maniobra de Valsalva y defecación cerrándose y abriéndose respectivamente (ANEMURMDP: 296).

67. Tomando como valor de corte de ADC $1.2 \times 10^{-3} \mathrm{~mm}^{2} / \mathrm{seg}$, la RMND logró identificar estos 4 casos (RMND: 50).

La segunda excepción la constituyen las marcas y nombres comerciales ${ }^{21}$, en casos en los que se especifique su registro con los símbolos ${ }^{\circledR}$ (registered trademark) o TM (trademark) pegados al término al que se refiere ${ }^{22}$ :

68. La media de edad de nuestros pacientes en el momento de inicio de la terapia VAC® fue de 23 días de vida (ASPNVAC: 110).

69. Tras visualizar la estenosis con el endoscopio se introdujo una guía, sobre la cual se realizó dilatación hidrostática con balón de $20 \mathrm{~mm}$ (Microinvasive ${ }^{\mathrm{TM}}$ ) (TEBD: 333).

70. El monitoreo es factible hasta $15 \mathrm{~m}$ de distancia. Se probó en distintos móviles de Nokia ${ }^{\circledR}$, Sony Ericsson ${ }^{\circledR}$ y Samsung ${ }^{\circledR}$ (MSEFC: 197).

71. Permite conexión con el sistema Flextrode@ (GRDME: 160).

72. Beating the Blues ${ }^{\mathrm{TM}}$ es un programa computerizado de terapia cognitivo comportamental (CCBT) para el tratamiento de la depresión y la ansiedad (EIPADAP: 42).

\footnotetext{
${ }^{21}$ Recordemos, además, que estas expresiones han de aparecer con mayúscula inicial, al tratarse de nombres propios (OLE, 2010: 502).

${ }^{22}$ En el caso de ${ }^{\mathrm{TM}}$, este ha de aparecer volado.
}

NORMAS. REVISTA DE ESTUDIOS LINGÜÍSTICOS HISPÁNICOS, NÚMERO 2 (AÑO 2012):

http://www.uv.es/normas 
Es un uso erróneo, pues, $-\mathrm{y}$ tal vez por influencia inglesa, ya que es así como se presentan en los textos anglosajones- la aparición en posición volada del símbolo de marca registrada ${ }^{\circledR}$, ya que debe presentarse en la misma línea de texto:

73. Quizás esta paciente fue la última que recibió tratamiento con $*$ Xigris ${ }^{\circledR}$ en nuestro hospital (PPSSTE: 6).

Por lo que respecta a la expresión de los grados de temperatura, la Ortografía (OLE, 2010: 590-1) admite dos formas de escritura distintas para esta. La primera de ellas es mediante su símbolo correspondiente $\left(^{\circ}\right)$ pegado a la cifra a la que se refiere, si no se acompaña con el símbolo de la escala $C$ o $F$ (Celsius o Fahrenheit, respectivamente). También se podría escribir, no obstante, separado de la cifra y pegado al símbolo de la escala, si esta se especifica. De esta manera, su empleo en los ejemplos 74, 75 y 76 sería incorrecto, por escribirse pegado a la cifra ${ }^{23}$, por aparecer ambos símbolos separados (el de la gradación térmica pegado a la cifra y separado por un espacio en blanco del indicador de la escala Celsius, o por aparecer ambos separados por un espacio:

74. La paciente ingresó en la UCI en donde se documentó la presencia de shock séptico (lactato venoso de $5,6 \mathrm{mmol} / \mathrm{L}$ y necesidad de drogas vasoactivas para mantener la hemodinamia) y una $\mathrm{T}^{\mathrm{a}}$ [temperatura axilar] de $* 37^{\circ} \mathrm{C}$ (PPSSTE: 2 ).

75. [el paciente] acude a Urgencias por presentar un cuadro de dolor abdominal acompañado de deposiciones diarreicas de 4 días de evolución, asociado a pico febril $\left(* 38,5^{\circ} \mathrm{C}\right)($ TGIST: 22$)$.

76. [las muestras] se pueden mantener en refrigeración a $* 4^{\circ} \mathrm{C}$ durante un máximo de 12 horas. Si van a pasar más de 12 horas es preferible conservarlas congeladas a una temperatura igual o inferior a $*-20^{\circ} \mathrm{C}($ AMMILM: 27$)$.

Así, si se opta por indicar la escala de temperatura empleada en la expresión, el uso que recoge la Ortografía, como se ha comentado, es el que se ofrece en los ejemplos 77 y 78 :

77. Al quinto día el paciente presentó fiebre de $38,5{ }^{\circ} \mathrm{C}$, secreciones bronquiales mucopurulentas (...) y un nuevo infiltrado pulmonar derecho (CIPCQ: 94).

78. (...) las válvulas se dividieron en dos partes, una de las cuales se congeló a $-80{ }^{\circ} \mathrm{C}$ para el futuro análisis (NDVA: 814).

${ }^{23}$ Obsérvese, además, que este ejemplo contiene otro error ortotipográfico, como es la ausencia del punto abreviativo obligatorio en la abreviatura $* T^{a}$ (que abreviaría, en el texto, la expresión «temperatura axilar»).

NORMAS. REVISTA DE ESTUDIOS LINGÜÍSTICOS HISPÁNICOS, NÚMERO 2 (AÑO 2012):

http://www.uv.es/normas 
Las escrituras gráficas $\min , h, d$, etc. son los símbolos que representan las expresiones numéricas referentes al tiempo cronológico (minutos, horas, días, etc. ${ }^{24}$ ). Al tratarse de símbolos internacionales, y no de abreviaturas, han de escribirse siempre sin punto, siguiendo el ejemplo de $\min$ y $h$ en el ejemplo siguiente ${ }^{25}$ :

79. La dosis de carga es de 4-6 g en 20 min, para posteriormente mantener infusión de 1$2 \mathrm{~g} / \mathrm{h}$ (PREEC: 196).

Por otra parte, en el mundo anglosajón y en Hispanoamérica los símbolos monetarios suelen aparecer antepuestos a la cifra a la que acompañan; en España, sin embargo, se prefiere su posposición, separados ambos elementos por un espacio en blanco $^{26}$ (OLE, 2010: 591):

80. El manejo de los pacientes con coledocolitiasis en un solo tiempo representó un ahorro de 3 días de estancia y $1.008 €$ por paciente (EMCHTC: 310$)$.

En otro orden de cosas, cuando el símbolo de un operador matemático sea binario (esto es, afecte a una operación que se realiza entre dos dígitos), este debe separarse entre espacios finos (OLE, 2010: 591), como en los ejemplos 81 y 82:

81. Hubo $16(0,020 \times 103)$ notificaciones de reacciones adversas a través del SIV [Sistema de Información Vacunal] (VNRAVGPE: 244).

82. [en un ensayo clínico] se analiza el número de infecciones en un grupo de pacientes tratado con amoxicilina-clavulánico $(\mathrm{n}=190)$ frente a otro que recibe placebo $(\mathrm{n}=$ 189), tras la intervención de reparación de hernia inguinal (ACPA: 270).

Son erróneas, por tanto, soluciones como las que se pueden observar en los ejemplos 83, 84 y 85, que presentan diversas operaciones matemáticas (como son la expresión de las dimensiones, la expresión exacta de una totalidad o la variabilidad de una cifra) sin ningún espacio en blanco que separe el símbolo de sus cifras circundantes:

\footnotetext{
${ }^{24}$ Recuérdese, como observa la Ortografía, que no se deben confundir los símbolos de minutos y segundos cronológicos (los aquí comentados, cuyos símbolos son min y $s$, respectivamente) «con los minutos y segundos utilizados en la expresión de la medida de los ángulos» (OLE, 2010: 591), cuyos símbolos son'y ".

${ }^{25}$ En el ejemplo, el punto posterior del símbolo $h$ se debe a que es un punto seguido; obsérvese, además, el uso correcto de $g$, símbolo de gramo.

${ }^{26}$ Manteniendo, coherentemente, la normativa general de la posposición de los símbolos. Nótese en el ejemplo, no obstante, la incorrección de separar mediante un punto los millares en *1.008€.
}

NORMAS. REVISTA DE ESTUDIOS LINGÜÍSTICOS HISPÁNICOS, NÚMERO 2 (AÑO 2012):

http://www.uv.es/normas 
83. Se decide completar el estudio con una tomografía computerizada en la que se confirma la presencia de la masa dependiente de intestino delgado, de $* 4 \times 5 \mathrm{~cm}$ de diámetro, con afectación de la grasa adyacente (TGIST: 22).

84. En cada paciente $(* n=160)$ se analizan 3 sesiones consecutivas $(* n=480$ sesiones $)$ (QICEDP: 118).

85. Se estudiaron 34 pacientes, $66 \%$ varones, edad media de $* 61.2 \pm 14$ años, 3 con poliquistosis renal, un índice de comorbilidad de Charlson medio de 7,9, un índice de masa corporal medio de $* 27.4 \pm 4.2$ y un tiempo medio en DP de $* 21 \pm 12$ meses. El volumen medio diurno fue de $* 1796 \pm 385 \mathrm{~mL}$ y el nocturno de $* 2100 \pm 254 \mathrm{~mL}$ (RPIDPHF: 94).

Sin embargo, cuando el símbolo matemático afecte a un único elemento, se debe escribir pegado a la cifra a la que acompaña:

86. FAV: *> $400 \mathrm{ml} / \mathrm{min}$, con límites de presiones arterial y venosa * \pm 250 y recirculación $*<15 \%$; CT: *> $350 \mathrm{ml} / \mathrm{min}$ sin colapsos (QICEDP: 117).

\section{INCORRECCIONES RELATIVAS A LAS EXPRESIONES NUMÉRICAS}

En el ámbito lingüístico panhispánico, en una expresión numérica con decimales, se han admitido tradicionalmente tanto la coma como el punto como signos de separación de la parte entera y la decimal, dependiendo de los países (OLE, 2010: 666) ${ }^{27}$. Sin embargo, actualmente la Ortografía, con el objetivo de iniciar un proceso tendente a la unificación, ha empezado a promover el punto como signo separador de decimales (OLE, 2010: 666). Por lo tanto, sería ya desaconsejable (aunque aún no incorrectos) usos de la coma como en el ejemplo 87, y pasan a ser preferibles las expresiones que se dan en 88 y $89^{28}$ :

87. Rivaroxaban presentó una eficacia (variable principal) no inferior al control, de 36 eventos $(* 2,1 \%)$ frente a 51 eventos con enoxaparina-AVK $(* 3,0 \%)$ (NAOTTVP: 214).

88. (...) comenzando a $5 \mathrm{~cm}$ del píloro y el resto con recargas azules de $3.5 \mathrm{~mm}$ hasta el ángulo de His (MEPSGVL: 39).

${ }^{27}$ Como especifica OLE (2010: 666), la coma como signo de separación de decimales se emplea en Sudamérica (concretamente, en Argentina, Chile, Colombia, Ecuador, Paraguay, Perú y Uruguay) y España, mientras que el punto se usa en Centroamérica (México, Guatemala, Honduras, Nicaragua, Panamá), el Caribe insular (Puerto Rico, República Dominicana) y también en Venezuela. Países como Bolivia, Costa Rica, Cuba y El Salvador emplean ambos indistintamente.

${ }^{28}$ Obsérvese, en este caso, además, la expresión incorrecta al emplear el símbolo del porcentaje (\%) sin su preceptiva separación de la cifra a la que acompaña. 
89. Los pacientes tratados con células madre tuvieron mayor FEVI a los seis meses con incremento de $0.7 \%$ en el grupo control, y $6.7 \%$ en el grupo de células madre (TCCI: 224).

Por otro lado, para separar los grupos de tres dígitos en la parte entera de un número entero (como los millares) no se debe utilizar ni el punto ni la coma. Aunque tradicionalmente se han solido emplear ambos signos como separadores en expresiones numéricas, la normativa internacional (como la Oficina Internacional de Pesos y Medidas y la ISO -International Organization for Standardization, 'Oficina Internacional para la Estandarización'- y la Oficina Internacional de Pesos y Medidas) dispone que no se emplee ninguno de los dos cuando el número expresa cantidad, por lo que se ha de insertar entre los bloques de tres dígitos un espacio en blanco fino (OLE, 2010: 663-4):

90. La mayoría de los ojos tenían un conteo celular endotelial por encima de 2500 , cifra comprendida dentro de los valores normales (MCOS [en línea]).

Son incorrectas, por lo tanto, las expresiones numéricas contenidas en los ejemplos 91, 92 (por la separación mediante punto) y 93 (al presentar separación mediante coma):

91. El comportamiento de las ventas de tabaco durante 2011 refleja una disminución de un $23,7 \%$ en las ventas de cigarrillos ( $* 858.709 .347$ cajetillas de 20 unidades, menos que en 2010) (PCTPT: 178).

92. Se administraron $* 692.854$ dosis de vacuna antigripal estacional y se registraron un total de $27(0,040 / 103)$ notificaciones de sospechas de reacciones adversas (VNRAVGPE: 245).

93. Si las infecciones estreptocócicas graves presentan una frecuencia de $1,4 / * 100,000,2$ su asociación con una peritonitis primaria todavía es más infrecuente (PPSSTE: 4).

Sin embargo, como se especifica en $O L E$ (2010: 664), el espacio fino separador no se empleará cuando el número no exprese cantidad, sino que sirva para identificar un elemento dentro de una serie (como años, páginas, textos legales, etc.):

94. La Ley 51/2003 destaca con la introducción del principio de accesibilidad universal, mientras que la Ley 39/2006 representa una fuerte apuesta por la eliminación de las barreras que garanticen un acceso igualitario y la participación plena (UDEA: 122).

NoRMAS. REVISTA DE ESTUdIOS LINGÜÍSTICOS HISPÁNICOS, NÚMERO 2 (AÑO 2012):

http://www.uv.es/normas 
Respecto a otras expresiones numéricas, y, en concreto, a la escritura de las décadas, la normativa académica, aunque se decanta por el empleo de los numerales cardinales, admite también la expresión de estas mediante cifras (OLE, 2010: 695). Así, en el ejemplo 95, resultan admisibles las expresiones de los años 50 y hasta los años 70, aunque la Academia admita su preferencia por la escritura de los años cuarenta y hasta los años setenta, respectivamente.

95. Fue Cosman el primero en construir un aparato de RF a principio de los años 50, aunque no se utilizó para tratar el dolor hasta los años 70 (GRDME: 157-158).

Lo que se calificaría como inadmisible serían las fórmulas *de los años 50 s, *hasta los años 70's o de los años '50 (es decir, con una s final como marca de plural, precedida esta o no de apóstrofo e, incluso, con apóstrofo pospuesto a la cifra), calcos del inglés.

Por otra parte, para la expresión de un porcentaje numérico, se puede recurrir al símbolo \%, correspondiente a la locución 'por ciento'. Este no aparecerá nunca sin separación de la cifra que lo preceda, sino que, como todos los símbolos, se escribirá separado por un espacio en blanco (que podrá ser un espacio fino, para evitar una separación excesiva) (OLE, 2010: 696-697):

96. La mayor cifra estuvo entre 60 y 79 años de edad con 45 pacientes $(48,4 \%)$, seguido por 22 pacientes mayores de 80 años $(23,7 \%)$ (CCPCCO2 [en línea]).

97. El $43 \%$ [de los pacientes] fueron varones, siendo la escala de ASA más habitual el tipo II $(63,16 \%)$ (MFP: 261).

El hecho de que aparezca el símbolo de porcentaje pegado a su cifra es un error que se comete con excesiva frecuencia en los textos de nuestro corpus, aunque mostremos aquí solo dos usos erróneos:

98. Los episodios de hemorragia mayor aparecieron en 20 pacientes con dabigatran $(* 1,6 \%)$ y en 24 con warfarina $(* 1,9 \%)$; los episodios de sangrado relevante (mayor + no mayor pero relevante) se observaron en 71 pacientes asignados a dabigatran $(* 5,5 \%)$ y 111 pacientes del grupo warfarina $(* 8,8 \%)$ (NAOTTVP: 213$)$.

99. (...) la incidencia de enfermedad invasiva con profilaxis fue del $* 3,9 \%$. La mortalidad de las formas invasivas es muy elevada y se cifra entre el 70 y el $* 100 \%$ (CIPCQ: 99). 
No hemos registrado en nuestro corpus, sin embargo, otras grafías erróneas con las que se han solido expresar incorrectamente los porcentajes, como *43 p. 100, *63 x 100 o *50/100 (cfr. Martínez de Sousa, 2008b: 504).

Cuando aparezcan varios porcentajes coordinados, la normativa académica recomienda, para evitar posibles confusiones, repetir el símbolo \% detrás de cada una de las cifras (OLE, 2010: 698), por lo que las expresiones semejantes al ejemplo 100 serán preferibles a las de los 101 y 102 :

100. [la preeclampsia] complica del 5\% al 7\% de todos los embarazos (PREEC: 197).

101. La incidencia observada de mastitis varía del 3 al 33\% de las mujeres en periodo de lactancia (AMMILM: 26).

102. Solamente en un 30 a $50 \%$ de los casos se realiza el diagnóstico correcto, incluso apoyado de medios complementarios, antes de la intervención quirúrgica (IB: 12).

No obstante, y como afirma Martínez de Sousa (2008b: 505), este uso puede resultar redundante, ya que parece haber una mínima posibilidad de confusión al entenderse claramente que el porcentaje se refiere a ambas cifras coordinadas.

A la normativa académica sí le parece más indicado, sin embargo, colocar un solo símbolo \% al final de intervalos de porcentajes separados por guion (OLE, 2010: 698 $)^{29}$ :

103. (...) se observa infiltración amiloide del tiroides en $* 50-80 \%$ de casos de amiloidosis secundaria (BA: 59).

104. Como se ha indicado anteriormente, el problema fundamental de este fármaco es la alta tasa de abandonos debido al dolor en la zona de inyección (*10-23\%) (UPC8: 135).

105. La presencia de dos de los tres primeros signos ocurre en un $* 40-50 \%$ de las veces y es considerado patognomónico de íleo biliar (IB: 13).

106. Del *10-15\% de los pacientes con cáncer de colon que presentan inestabilidad de los microsatélites, aproximadamente un $* 70-80 \%$ muestran silenciamiento epigenético de $M L H 1$, un gen que procura reparar los errores por incompatibilidad entre bases (EYCC: 280).

Por otro lado, los numerales ordinales, cuando no se expresen en letra, sino en número, deben escribirse con la terminación correspondiente volada, precedida siempre

${ }^{29}$ Aunque, como puede observarse, se expresa incorrectamente el intervalo de porcentajes, al no aparecer un espacio en blanco que separe el símbolo \% de las cifras a las que se refiere.

NORMAS. REVISTA DE ESTUDIOS LINGÜÍSTICOS HISPÁNICOS, NÚMERO 2 (AÑO 2012):

http://www.uv.es/normas 
de un punto abreviativo, ya que nos encontramos, en realidad, ante abreviaturas formadas por contracción (cfr. OLE, 2010: 572; Martínez de Sousa, 2008a: 189 y 195):

107. La IPA [inflamación periaórtica] media preoperatoria fue de $14 \mathrm{~mm}(\mathrm{DE} 1,7)$, evidenciándose adherencias a la 3. ${ }^{\mathrm{a}}$ porción del duodeno (RRQAI: 308).

Serían incorrectos, pues, los dos siguientes usos (108) y (109), al no presentar su punto abreviativo preceptivo $^{30}$ :

108. Las causas seleccionadas, para todo el periodo, fueron codificadas con la Clasificación Internacional de Enfermedades *10ª revisión (CIE-10) (APVDEMDA: 220).

109. El estudio definitivo puso de manifiesto (...) una adenopatía invadida de las cuatro obtenidas en el examen del tejido linfograso, pT3N1M0, estadio IIb de la clasificación TNM revisada ( $* 6^{\circ}$ edición), III de la $* 5^{\circ}$ edición TNM (CBT2P: 17).

\section{ALGUNOS USOS INCORRECTOS DE LAS LETRAS MAYÚSCULAS}

De entre los usos erróneos de la letra mayúscula más reiterados que hemos apreciado en nuestro corpus, querríamos destacar aquí algunos de los que nos parecen más interesantes, como son la difusión de la mayúscula enfática (sobre todo, con nombres de enfermedades) y diversas incorrecciones respecto a la nomenclatura científica en términos latinos, a las entidades relacionadas con la medicina y a los nombres de los meses del año.

En los textos estudiados se observa una general profusión de lo que la Ortografía denomina la mayúscula «de relevancia» o «enfática» (OLE, 2010: 514), mediante la que el autor, pretendiendo otorgar relevancia al referente y movido por diversas razones subjetivas, escribe impropiamente en mayúscula la inicial de la palabra que pretende destacar $^{31}$ :

\footnotetext{
${ }^{30}$ Nótese, en el segundo ejemplo, que las dos letras voladas $\left(^{\circ}\right)$ hasta carecen de concordancia de género con los sustantivos a los que van referidas, pues al referirse a al término edición la expresión correcta debería haber sido $6 .^{a}$ edición y $5 .^{a}$ edición, respectivamente.

31 En Martínez de Sousa (2008a: 241-2), se puede encontrar un minucioso análisis de esta injustificada mayusculización de sustantivos comunes, dividida en diversos tipos como la mayúscula estilística, la diacrítica, la subjetiva, la de dignidad, la genuflexiva y la de ornato.
}

NORMAS. REVISTA DE ESTUDIOS LINGÜÍSTICOS HISPÁNICOS, NÚMERO 2 (AÑO 2012):

http://www.uv.es/normas 
110. [los monómeros de resina] al polimerizar quedan atrapadas en ella [superficie dentinaria], conformando una estructura mixta denominada * Capa Híbrida (MCHDSA: 134).

111. Una vez introducido el esfinterotomo en la *Papila de Vater, en la teórica zona del colédoco, se hizo avanzar la guía (CPREDE: 54).

Se ha observado cierta tendencia a escribir incorrectamente con mayúscula inicial los nombres de las enfermedades, uso relacionado en cierta medida con la «mayúscula subjetiva» que analiza Martínez de Sousa (2008a: 242). Sin embargo, la Ortografía establece que los nombres de enfermedades se escribirán siempre con minúscula (OLE, 2010: 501), por lo que frente a los casos 112, 113 y 114, recomendamos el uso en minúscula del ejemplo 115 -obtenido, por cierto, del mismo trabajo que el artículo del caso 113-:

112. Dos de los tres enfermos con *Poliquistosis renal sufrieron una fuga pericatéter (RPIDPHF: 98).

113. ¿Qué son la *Anorexia y la *Bulimia? La anorexia es un trastorno alimentario, caracterizado por la ausencia anormal de apetito (MTCTCA [en línea]).

114. Las radiografías de cráneo y tórax fueron realizados y no mostró cambios (Figs. 5 y 6). Luego completó un diagnóstico de *Plasmocitoma solitario en la mandíbula (FMPPI: 121).

115. Dentro de estas patologías de base psicoafectiva, encontramos la anorexia nerviosa y la bulimia nerviosa, en las que a lo mencionado anteriormente de nuestra sociedad, sumamos la personalidad de dichos pacientes (MTCTCA [en línea]).

Esta mayusculización de los nombres de enfermedades (y otros sustantivos comunes) se extiende con relativa frecuencia, sobre todo, a los títulos de los artículos, hecho que se podría explicar por influencia del inglés y a su prodigalidad a la hora de emplear esta clase de letra (cfr. Martínez de Sousa, 2008b: 152-3):

116. Actualización en el manejo de las *Mastitis *Infecciosas durante la *Lactancia *Materna (AMMILM: 28).

117. Disfagia en un adolescente como manifestación de la *Esofagitis *Eosinofílica (DAMEE: 54).

NORMAS. REVISTA DE ESTUDIOS LINGÜÍSTICOS HISPÁNICOS, NÚMERO 2 (AÑO 2012):

http://www.uv.es/normas 
118. Distribución de la FDG PET/TAC en la enfermedad de Castleman simulando *Linfoma (FDGPETTAC: 142).

En cambio, si los nombres de enfermedades formaran parte de expresiones denominativas, estos se han de escribir con letra mayúscula (OLE, 2010: 501):

119. [la eventración suprapúbica], según la clasificación de la Sociedad Europea de Hernia, se denomina con la sigla M5 (ES: 545).

Deben escribirse con letra minúscula inicial los nombres de los principios activos de las medicinas bajo los cuales se comercializan los medicamentos genéricos (OLE, 2010: 502):

120. Debido a su eficacia y seguridad, el fluconazol puede ser seleccionado como tratamiento de primera línea en pacientes con sospecha o documentación de candidiasis invasiva (OTTAPC: 108).

121. Una de las principales ventajas del voriconazol en los tratamientos combinados es la posibilidad de administrarse por vía oral (APPCNI: 92).

122. La amoxicilina se absorbe amplia y rápidamente por vía oral (biodisponibilidad oral de $75 \%$ ), aunque la comida puede retrasar la absorción (ACPA: 274).

123. (...) recibiendo [la paciente] el alta hospitalaria a los siete días de su ingreso con una rápida recuperación tras tratamiento antibioterápico de amplio espectro (piperacilina-tazobactan y metronidazol) ante peritonitis por flora múltiple de origen intestinal (RIMEPSED: 10).

Sin embargo, las marcas y los nombres comerciales registrados de los medicamentos se han de escribir con mayúscula inicial. Se suele recomendar, en este tipo de publicaciones científicas, que se especifique su registro con los símbolos ${ }^{\mathrm{TM}}$ (siempre volado) o ${ }^{\circledR}$ (que en español, al contrario que en inglés, nunca se escribe volado, sino al mismo nivel del texto):

124. Vacunas antigripales incluidas en el estudio. (...) Chiromas ${ }^{\circledR}$ de Laboratorio Novartis Vaccines and Diagnostics SL, vacuna virus fraccionados adyuvada con MF5929. Inflexal V® de laboratorio Crucell, vacuna de antígeno de superficie, inactivado, virosomal. Influvac $®$ del laboratorio Abbott Healthcare, vacuna antigripal inactivada de antígenos de superficie (VNRAVGPE: 244).

NORMAS. REVISTA DE ESTUDIOS LINGÜÍSTICOS HISPÁNICOS, NÚMERO 2 (AÑO 2012):

http://www.uv.es/normas 
Por ello, el ejemplo 125 sería incorrecto al no especificar el registro del nombre comercial de la pomada en cuestión, mientras que el 126 presenta el empleo erróneo de la marca de registro volada:

125. Indicaron tratamiento tópico con cromoglicato al $2 \%$ y pomada *Protopic $0,1 \%$ (tacrolimus) y prednisona oral (PGEAP: 92).

126. Planteamos la posibilidad de tratamiento con parche de capsaicina $8 \%$ $\left({ }^{*}\right.$ Qutenza $\left.^{\circledR}\right)$ de forma experimental, indicando al paciente su uso fuera de ficha técnica (UPC8: 134).

En los textos de carácter científico-técnico, cuando aparece un nombre latino para la nomenclatura científica que designa especies y subespecies de animales y plantas, el primer componente de este (que es el descriptivo del género) se debe escribir con mayúscula inicial, pero la inicial del segundo (el específico de la especie) y del tercero (el específico de la subespecie) se escribirán con minúscula (OLE, 2010: 473-4). Además, estos nombres científicos, al tratarse de voces procedentes de una lengua distinta a la española (la latina, en concreto), han de marcarse con letra cursiva (OLE, 2010: 474; Aleza, 2011: 96). En las publicaciones médicas este uso suele darse, por ejemplo, en textos que tratan sobre microorganismos que originan procesos infecciosos, aunque puede encontrarse, en realidad, en cualquier tipo de trabajo que cite el nombre científico de cualquier especie animal o vegetal:

127. En nuestro país pueden producirse picaduras por arañas venenosas del tipo Loxosceles rufescens o araña de rincón, Latrodectus tridecimguttatus o viuda negra y Lycosa tarantula o tarántula (LC: 73).

128. El síndrome del shock tóxico estreptocócico (streptococcal toxic shock síndrome, STSS) es el shock séptico y fracaso multiorgánico producido por la infección de un estreptococo del grupo A, Streptococcus pyogenes (PPSSTE: 2).

Son erróneas, por lo tanto, las denominaciones que se ofrecen en los casos siguientes:

129. Clásicamente se ha asociado el *s. aureus a la producción de mastitis, a diferencia de lo que ocurre con *s. epidermidis cuyo papel en la etiología de esta infección se podría haber infravalorado (AMMILM: 26).

130. El virus del papiloma humano (VPH) forma parte de la familia de los *Papillomaviridae y puede originar lesiones papilomatosas, verrucosas e hiperplásicas que afectan a la piel y a las mucosas ( $P B P P: 46)$.

NORMAS. REVISTA DE ESTUDIOS LINGÜÍSTICOS HISPÁNICOS, NÚMERO 2 (AÑO 2012):

http://www.uv.es/normas 
131. Dentro de ellos, los estafilococos cuagulasa negativos, especialmente el *s. epidermidis, probablemente están implicados en la mayoría de las mastitis (AMMILM: 26).

Sin embargo, cuando la nomenclatura científica se emplee de forma hispanizada y como adjetivo o nombre común, se escribirá con minúscula inicial y, además, en letra redonda, como el término estafilococos cuagulasa negativos del ejemplo anterior (131) o como en el siguiente:

132. Los estafilococos cuagulasa-negativos (...) no deben considerarse como "flora contaminante" (AMMILM: 28).

Los nombres de departamentos, instituciones, unidades y servicios quirúrgicos, etc. se escriben con mayúscula inicial (OLE, 2010: 482-483), como en los ejemplos siguientes:

133. Se contactó con el Servicio de Oncología y dada la estirpe tumoral no se indicó ningún tratamiento adyuvante (CBT2P: 17).

134. Ocasionalmente se midió la radiación por parte del Servicio de Radiofísica (CPREDE: 54).

135. Retiramos estos [los puntos] en nuestra consulta, o a través de la Unidad de Hospitalización Domiciliaria (ES: 550).

136. Esto incluye a nombres comunes (del tipo hospital, universidad, departamento, etc.) que formen parte de expresiones denominativas de entidades, organismos e instituciones, se escribirán con mayúscula inicial ${ }^{32}$ :

137. El objeto a estudio ha sido las instalaciones de la unidad de diálisis del USP Hospital Santa Teresa de A Coruña (UDEA: 123).

138. los cuales [pacientes] fueron intervenidos en la Unidad de Cirugía Endoscópica del Servicio de Cirugía II, en el Hospital Universitario de Caracas (MEPSGVL: 38).

${ }^{32}$ Obsérvese, no obstante, en el ejemplo 136, que la sección organizativa *unidad de análisis se expresa con minúsculas iniciales, obviando la norma anterior.

NORMAS. REVISTA DE ESTUDIOS LINGÜÍSTICOS HISPÁNICOS, NÚMERO 2 (AÑO 2012):

http://www.uv.es/normas 
Sin embargo, ese mismo nombre común se escribirá con minúscula cuando actúe como mero clasificador, sin formar parte de una expresión denominativa (OLE, 2010: 461) y, sobre todo, en denominaciones anafóricas (OLE, 2010: 484), un error frecuente en nuestro corpus:

139. En nuestro *Centro hemos desarrollado un programa de formación basado en ergonomía (ECL: 288).

140. Todos los procedimientos fueron aprobados por el Comité de Bioética y Docencia e Investigación del Hospital de Clínicas José de San Martín. Los procedimientos se realizaron en el Centro de Cirugía Experimental del Departamento de Cirugía del *Hospital (UVIFICB: 20).

Por último hemos de comentar que, al contrario que en inglés, los nombres de los días de la semana y de los meses del año deben escribirse con minúscula inicial (OLE, 2010: 502):

141. Se incluyó a aquellos pacientes $\geq 65$ años que ingresaron de forma transitoria en convalecencia y/o larga estancia desde el 1 de enero de 2009 al 31 de diciembre de 2010 (FRECPAICS: 70).

La no observancia de la norma anterior supone un anglicismo ortotipográfico que ha de evitarse en todo momento (cfr. Martínez de Sousa, 2008b: 153):

142. En *Diciembre de 2010 consultó de nuevo por episodios de atragantamiento cada vez más frecuentes y de mayor duración, precisando de ciertas maniobras como la ingesta abundante de líquido (DAMEE: 54).

143. La recopilación de los datos ha sido realizada en *Octubre de 2011. Los datos se han organizado en tablas (UDEA: 123).

\section{CONCLUSIONES}

En el presente artículo hemos pretendido ofrecer, de manera sucinta, algunas de las incorrecciones ortotipográficas en las que suelen incurrir frecuentemente un tipo específico de publicaciones de carácter científico-técnico cuya importancia para la transmisión y el progreso del conocimiento científico humano nos parece fundamental, tal y como son las publicaciones del ámbito médico-quirúrgico, en las que consideramos 
que el cuidado de la expresión y la corrección lingüística han de ser extremos, ya que en ellas no ha de caber lugar para equívocos, imprecisiones e incorrecciones y juegan un papel primordial en la formación científica de futuras generaciones de profesionales sanitarios. Sin evaluar cuestiones estilístico-expresivas, puntuación, tipo de letra (redonda, cursiva), etc., hemos comentado, partiendo de un corpus representativo, los errores ortotipográficos más frecuentes que suelen presentar las publicaciones científico-médicas en español a ambos lados del Atlántico (tales como las relativas a la prefijación y al empleo de abreviaturas, siglas, símbolos y letras mayúsculas).

Como se ha podido ir demostrando a lo largo del trabajo, dos parecen ser las causas principales de los incorrecciones y empleos impropios de la ortotipografía que propugna la normativa académica: en primer lugar, la enorme influencia que ejerce la lengua inglesa en este tipo de publicaciones, hecho que favorece la imitación ortotipográfica (consciente e inconsciente); en segundo lugar, el desconocimiento de la normativa por parte de los profesionales médico-quirúrgicos $-\mathrm{y}$, en algunos casos, precisamente lo contrario: su no aplicación consciente ante las normas e innovaciones que conocen, como podrían ser las nuevas normas de acentuación gráfica publicadas por la Ortografía (OLE, $2010)^{33}$-. Solo un conocimiento profundo de la ortotipografía española y la voluntad de unificar dichos criterios en todo el ámbito panhispánico podría conseguir que se evite la profusión de errores que encontramos (generalmente, calcos de la lengua inglesa); por otra parte, por lo que respecta al desconocimiento de la ortotipografía por parte de los autores de publicaciones científicas en español, podemos pensar que aún parece pronto para que se aplique completamente la nueva normativa académica, que cuenta con solo dos años desde su publicación, por lo que tendrá que pasar más tiempo para que este intento de unificación se asimile por completo.

\section{REFERENCIAS BIBLIOGRÁFICAS}

AlEZA IZQUIERO, Milagros (2011) Signos ortográficos, ortotipografía y normas actuales, Valencia, Universitat de València (Anejo didáctico núm. 1 de Normas. Revista de Estudios Lingüísticos Hispánicos).

<https://www.uv.es/normas/Signos_2011>. [Consulta: 26/09/2012].

\footnotetext{
${ }^{33}$ Recordemos que contamos con trabajos que analizan las distintas recepciones contrarias y de rechazo que ha suscitado la nueva Ortografía académica, como, por ejemplo, González (2011), centrado en el grado de aceptación de esta en las redes sociales.
} 
GONZÁLEZ GARCÍA, Virginia (2011): «"Me niego a que la i griega pase a llamarse ye": los usuarios de internet ante la Ortografía y el Diccionario de la Real Academia Española». Normas. Revista de Estudios Lingüísticos Hispánicos, 1: 93-111. <http://www.uv.es/normas/2011/Gonzalez_2011.pdf>. [Consulta: 02/10/2012].

MARTín CAMACHO, José Carlos (2004): El vocabulario del discurso tecnicocientífico, Madrid, Arco/Libros.

MARTínez de Sousa, José (1999): Diccionario de ortografía técnica, Madrid, Fundación Germán Sánchez Ruipérez.

MARTíNeZ DE SOUSA, José (2008a): Ortografía y ortotipografía del español actual, Gijón, Trea, 2. ${ }^{\text {e edición. }}$

MARTíneZ De SousA, José (2008b): Manual de estilo de la lengua española (MELE3), Gijón, Trea, 3. a edición, revisada y ampliada.

Real ACAdemia EsPañola (2001): Diccionario de la lengua española, Madrid, Espasa.

REAL ACADEMia EsPañola Y Asociación DE ACADEMias DE LA LENGUA ESPAÑOLA (2005): Diccionario panhispánico de dudas, Madrid, Santillana.

REAl ACADEMia EsPañola y Asociación de ACAdEMias dE LA LENGUA ESPAÑOLA (2010): Ortografía de la lengua española (OLE), Madrid, Espasa.

\section{Publicaciones científicas citadas}

(ACPA) CAÍnZos Fernández, Miguel y Carlos RodríGuez Moreno (2012): «Antibióticos y cirugía de la pared abdominal», en CARBONELL TATAY, Fernando y Alfredo MORENO EgEA, (coords.) Eventraciones. Otras hernias de pared y cavidad abdomina, 269-280.

(ALFSEV) MASANA, Lluís et al. (2012): «La adición de leche fermentada suplementada con esteroles vegetales mejora el cumplimiento de los cambios en el estilo de vida en los pacientes hipercolesterolémicos. Estudio RECIPE», Clínica e Investigación en Arterioesclerosis, 24, 4, 173-180.

$<$ http://www.elsevier.es/es/abstract/revistas/clinica-e-investigacionarteriosclerosis-15/la-adicion-leche-fermentada-suplementada-esteroles-vegetales90148428-originales-2012>. [Consulta: 26/09/2012]. 
(AMMILM) VAyas AbasCal, Rocío y Luis CARRera Romero (2012): «Actualización en el manejo de las Mastitis Infecciosas durante la Lactancia Materna», Revista Clínica de Medicina de Familia, 5, 1, 25-29:

<http://scielo.isciii.es/pdf/albacete/v5n1/especial1.pdf>. [Consulta: 28/09/2012].

(AMPRRMa) Garamendi, Pedro Manuel y M. LóPEZ AlCARAZ (2012): «Ataque mortal por perros de raza rottweiller a una mujer adulta: posible ataque en manada y antropofagia postmortal. Revisión y análisis de un caso de autopsia médico legal», Cuadernos de Medicina Forense, 18, 2, 71-80.

<http://scielo.isciii.es/pdf/cmf/v18n2/original3.pdf >. [Consulta: 26/09/2012].

(ANEMURMDP) MARTín MARTÍN, Gonzalo, Juan GARCÍA ARMENGOl et al. (2012): «Análisis de nuestra experiencia mediante el uso de resonancia magnética dinámica pelviana en la evaluación del síndrome de defecación obstuctiva», Cirugía Española, 90, 5, 292-297:

<http://www.elsevier.es/es/revistas/cirugia-espa\%C3\%B1ola-36/analisis-nuestraexperiencia-mediante-uso-resonancia-magnetica-90135009-originales-2012?bd=1 > . [Consulta: 28/09/2012].

(APPCNI) ÁlVARez LERMA, Francisco y Ana Rey PÉREZ (2012): «Aspergilosis pulmonar en un paciente crítico no inmunodeprimido», Revista Iberoamericana de Micología, 29, 2, 90-92:

<http://www.elsevier.es/es/revistas/revista-iberoamericana-micologia290/aspergilosis-pulmonar-un-paciente-critico-no-inmunodeprimido-90119301-casosclinicos-2012>. [Consulta: 28/09/2012].

(APVDEMDA) RUIZ RAMOS, Miguel (2012): «Análisis de las principales variables determinantes de la evolución de la mortalidad por demencias en Andalucía», Revista Española de Salud Pública, 86, 3, 219-228:

$<$ http://www.msc.es/biblioPublic/publicaciones/recursos_propios/resp/revista_cdr om/vol86/vol86_3/RS863C_219.pdf $>$. [Consulta: 26/09/2012].

(ASPNVAC) PÉREZ SAMPERE, María et al. (2012): «Aplicación del sistema de presión negativa VAC® en dehiscencia postesternotomía media en pacientes neonatos», Cirugía Plástica Ibero-Latinoamericana, 38, 2, 107-104:

<http://scielo.isciii.es/pdf/cpil/v38n2/original2.pdf >. [Consulta: 28/09/2012].

(BA) Pons, Albert, Amadeo MunTané et al. (2012): «Bocio amiloide: A propósito de un caso», Revista Chilena de Radiología, 18, 2, 59-61:

<http://www.scielo.cl/pdf/rchradiol/v18n2/art04.pdf>. [Consulta: 28/09/2012]. 
Carbonell Tatay, Fernando y Alfredo Moreno Egea, coords. (2012): Eventraciones. Otras hernias de pared y cavidad abdominal, Valencia, Ethicon.

(CBT2P) MORERA OCÓN, J., J. BALlestín ViCENTE et al. (2012): «Cáncer de vesícula T2 postcolecistectomía», Casos Clínicos de Cirugía General, 4, 1, 16-20:

$<$ http://www.aecirujanos.es/revista_cirugia_casos_clinicos/revista_casos_clinicos _cirugia_general_N7.pdf $>$. [Consulta: 26/09/2012].

(CCPCCO2) RAmíREZ GARCíA, Lázara Kenia, M. ${ }^{a}$ del Carmen GuAYACuma MeNDOZA et al. (2012): «Caracterización de las cirugías palpebrales con láser de $\mathrm{CO}_{2}$ », Revista Cubana de Oftalmología, 25, 1 (en línea):

$<$ http://new.medigraphic.com/cgibin/resumen.cgi?IDREVISTA=270\&IDARTICU

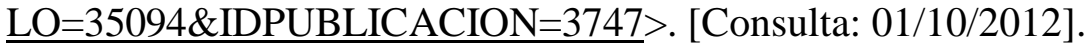

(CIPCQ) Amaya VILlar, Rosario (2012): «Candidiasis invasora en el paciente crítico quemado», Revista Iberoamericana de Micología, 29, 2, 93-96:

$<$ http://www.elsevier.es/es/revistas/revista-iberoamericana-micologia290/candidiasis-invasora-paciente-critico-quemado-90119302-casos-clinicos-2012> .

[Consulta: 28/09/2012].

(CIPSRU) De Merlo Martínez, Pelayo et al. (2012): «Candidiasis invasora en una paciente sometida a retrasplante unipulmonar», Revista Iberoamericana de Micología, 29, 2, 97-101:

$<$ http://www.elsevier.es/es/revistas/revista-iberoamericana-micologia290/candidiasis-invasora-una-paciente-sometida-retrasplante-unipulmonar-90119303casos-clinicos-2012?bd=1>. [Consulta: 28/09/2012].

(CIVMA) ROMERo Romero G. E. et al. (2012): «Comparación in vitro de la microfiltración apical del MTA y Angelus en dientes monorradiculares», Avances en Odontoestomatología, 28, 3, 125-131:

$<$ http://scielo.isciii.es/scielo.php?pid=S021312852012000300003\&script=sci_arttext>. [Consulta: 26/09/2012].

(CLIUARN) Moreno SAnz, Carlos, Antonio MorandeIRA Rivas, Salvador MoraLES CONDE et al. (2012): «Cirugía laparoscópica a través de incisión única. Análisis del registro nacional», Cirugía Española, 90, 5, 298-309:

$<$ http://www.elsevier.es/es/revistas/cirugia-espa\%C3\%B1ola-36/cirugialaparoscopica-traves-incision-unica-analisis-registro-90135010-originales-2012? bd=1 >

[Consulta: 01/10/2012]. 
(CPREDE) García CANo, Jesús, Manuel PÉRez Miranda et al. (2012): «CPRE durante el embarazo», Revista Española de Enfermedades Digestivas, 104, 2, 53-58:

$<$ http://scielo.isciii.es/scielo.php?pid=S113001082012000200001\&script=sci_artt ext\&tlng=es>. [Consulta: 28/09/2012].

(DAMEE) Orgaz Gallego, M. ${ }^{\mathrm{a}}$ Pilar et al. (2012): «Disfagia en un adolescente como manifestación de la Esofagitis Eosinofílica», Revista Clínica de Medicina de Familia, 5, 1, 53-58:

$<$ http://scielo.isciii.es/scielo.php?pid=S1699695X2012000100010\&script=sci_arttext>. [Consulta: 28/09/2012].

(ECL) PÉREZ DuARTE, Francisco Julián et al. (2012): «Ergonomía en cirugía laparoscópica y su importancia en la formación quirúrgica», Cirugía Española, 90, 5, 284291:

<http://www.sciencedirect.com/science/article/pii/S0009739X11002168\#>.

[Consulta: 01/10/2012].

(EDCG) MonTENEGRo QuesadA, Erick (2012): «Enfermedad divertícular. Cirugía General», Revista Médica de Costa Rica y Centroamérica, LXIX, 602, 175-178:

<http://www.binasss.sa.cr/revistas/rmcc/602/art2.pdf >. [Consulta: 01/10/2012].

(EGSEMI) JiMÉNEZ JimÉNEZ, Sagrario, Francisca MuElAs OrtegA et al. (2012): «Evaluación global subjetiva y escala de malnutrición-inflamación para valorar el estado nutricional de pacientes en diálisis peritoneal con hipoalbuminemia», Enfermería Nefrológica, $\quad 15, \quad 2, \quad 87-93: \quad<$ http://scielo.isciii.es/scielo.php?pid=S225428842012000200002\&script=sci_arttext $>$. [Consulta: 28/09/2012].

(eipadap) Latorre Postigo, José Miguel, Beatriz Navarro Bravo et al. (2012): «Evaluación e intervención de los problemas de Ansiedad y Depresión en Atención Primaria: Un problema sin resolver», Revista Clínica de Medicina de Familia, 5, 1, 37-45:

<http://scielo.isciii.es/pdf/albacete/v5n1/especial3.pdf>. [Consulta: 26/09/2012].

(EMCHTC) JORBA MARTÍN, Rosa, Elena RAMÍREZ MALDONADO et al. (2012): «Estudio de minimización de costes hospitalarios en el tratamiento de la coledocolitiasis», Cirugía Española, 90, 5, 310-317:

$<$ http://www.elsevier.es/es/revistas/cirugia-espa\%C3\%B1ola-36/estudiominimizacion-costes-hospitalarios-tratamiento-coledocolitiasis-90135011-originales2012?bd=1 >. [Consulta: 01/10/2012]. 
(es) Carbonell Tatay, Fernando y Santiago Bonafé Diana (2012): «Eventración suprapúbica. Técnica de Stoppa modificada», en CARBOnELl TATAY, Fernando y Alfredo MORENO EGEA, coords., 2012: op. cit., 545-552.

(EYCC) MenÉndez, Pablo, Pedro Villarejo et al. (2012): «Epigenética y cáncer colorrectal», Cirugía Española, 90, 5, 277-283:

$<$ http://www.elsevier.es/es/revistas/cirugia-espa\%C3\%B1ola-36/epigeneticacancer-colorrectal-90135007-revision-conjunto-2012>. [Consulta: 01/10/2012].

(FDGPETTAC) Elboga, U., Y. Narin et al. (2012): «Distribución de la FDG PET/TAC en la enfermedad de Castleman simulando Linfoma», Revista Española de Medicina Nuclear, 31, 3, 142-144:

<http://www.elsevier.es/es/revistas/revista-espa\%C3\%B1ola-medicina-nuclear-eimagen-molecular-125/distribucion-fdg-pettac-enfermedad-castleman-simulandolinfoma-90130624-notas-clinicas-2012>. [Consulta: 28/09/2012].

(FMPPI) ANTUNES FREITAS, D., C. I. VERGARA HERNÁNDEZ et al. (2012): «Fractura mandibular patológica por plasmocitoma intraóseo», Avances en Odontoestomatología, 28, 3, 119-124: <http://scielo.isciii.es/scielo.php?pid=S0213$12852012000300002 \&$ script=sci_arttext $>$. [Consulta: 28/09/2012].

(FRECPAICS) GuIL SÀNCHEZ, J., M. RodRÍGueZ-MARTín (2012): «Factores de riesgo y enfermedades cardiovasculares en la población anciana ingresada en un centro sociosanitario», Hipertensión y Riesgo Vascular, 29, 3, 69-74. <http://www.sciencedirect.com/science/article/pii/S1889183712000281\#>.

[Consulta: 28/09/2012].

(FRPETI) VÁZQUEZ ARCE, M. ${ }^{a}$ Isabel et al. (2012): «Fisioterapia respiratoria en pacientes con eventración. Tratamiento integral», en CARBONELL TATAY, Fernando y Alfredo MoREno EGEA, coords., 2012, op. cit., 795-800.

(GRDME) DE ANDRÉS J., G. RoCA, A. PERUCHO et al. (2012): «Generadores de radiofrecuencia disponibles en el mercado español», Revista de la Sociedad Española del Dolor, 19, 3, 157-164:

<http://scielo.isciii.es/pdf/dolor/v19n3/tecnicas.pdf $>$. [Consulta: 26/09/2012].

(GVLEVG) BELLO, Ígor Armando, Jenny Rosario GUEVARA et al. ,2011): «Gastrectomía vertical laparoscópica: estudio del vaciamiento gástrico», Revista Venezolana de Cirugía, 64, $\quad 2, \quad 37-41:$ $<$ http://www.sociedadvenezolanadecirugia.org/svc/revistas/revista_vol64_2/index.html>. [Consulta: 26/09/2012]. 
(HLPFP) Medezo Viadero, Raquel, Mirian García Martínez et al. (2012): «Hemodiafiltración en línea pre-dilucional, frente a post-dilucional: estudio comparativo de eficacia dialítica y tolerancia hemodinámica», Enfermería Nefrológica, 15, 2, 108-112:

<http://scielo.isciii.es/pdf/enefro/v15n2/original4.pdf>. [Consulta: 28/09/2012].

(ib) González Torres, C. G., J. C. AvendaÑo et al. (2012): «ĺleo Biliar. A propósito de un caso», Casos Clínicos de Cirugía General 4, 1, 11-15:

$<$ http://www.aecirujanos.es/revista_cirugia_casos_clinicos/revista_casos_clinicos _cirugia_general_N7.pdf $>$. [Consulta: 28/09/2012].

(LC) HERNÁNDEZ PÉREZ, Natacha et al. (2012): «Loxoscelismo cutáneo», Revista Clínica de Medicina de Familia, 5, 1, 73-75: $<$ http://scielo.isciii.es/scielo.php?pid=S1699-695X2012000100015\&script=sci_arttext $>$. [Consulta: 28/09/2012].

(MCHDSA) VALENZUELA ARÁNGUIZ, V. et al. (2012): «Micromorfología de la capa híbrida de dos sistemas adhesivos. Análisis al MET», Avances en Odontoestomatología, 28, 3, 133-140: $\quad<$ http://scielo.isciii.es/scielo.php?pid=S021312852012000300004\&script=sci_arttext $>$. [Consulta: 28/09/2012].

(mCOS) Gómez CAstillo, Zulema, Keyly Fernández García et al. (2012): «Microscopia confocal en córneas de cien ojos sanos», Revista Cubana de Oftalmología, 25, 1 (en línea): $<$ http://new.medigraphic.com/cgibin/contenido.cgi?IDREVISTA=270\&IDPUBLICACION=3747>. 01/10/2012].

(MEPSGVL) SÁNCHEZ-FigUEROA, N. et al. (2012): «Manometría esofágica en pacientes sometidos a gastrectomía vertical laparoscópica. Servicio de Cirugía Dos», Revista Venezolana de Cirugía, 64, 2, 42-47:

$<$ http://www.sociedadvenezolanadecirugia.org/svc/revistas/revista_vol64_2/index .ht-ml>. [Consulta: 26/09/2012].

(MFP) MORALES CONDE, Salvador et al. (2012): «Métodos de fijación de las prótesis: suturas, grapas y pegamentos en la cirugía abierta laparoscópica de la eventración», en CARbonell TATAY, Fernando y Alfredo Moreno EgEA, coords., 2012, op. cit., 255262.

(MHC2TA) Delgadillo, Hilda, Gilberto VARgas AlarCón et al. (2012): «Los polimorfismos del gen $M H C 2 T A$ no se asocian con la reestenosis después del implante de stent coronario en pacientes mexicanos», Archivos de Cardiología de México, 82, 3, 208-213: 
$<\underline{\text { http://www.elsevier.es/es/abstract/revistas/archivos-cardiologia-mexico-293/los- }}$ polimorfismos-gen-mhc2ta-no-se-asocian-90154183-investigacion-clinica-2012?bd=1 > . [Consulta: 26/09/2012].

(MSEFC) BECERRA LUNA, Brayans, Rodrigo DÁVILA GARCíA et al. (2012): «Monitor de señales de electrocardiografía y frecuencia cardiaca mediante un teléfono móvil con el protocolo de comunicación Bluetooth», Archivos de Cardiología de México, 82, 3, 197203:

$<$ http://www.archivoscardiologia.org.mx/historico/VOL.\%2082\%20A\%D10\%20 82\%20\%282012\%29/NUMERO\%203/07-9.pdf>. [Consulta: 28/09/2012].

(MTCTCA) MiÑAnO, Juan G. (2012): «Medicina Tradicional China en trastornos de conducta alimentaria», Revista Natural (en línea):

<http://www.revistanatural.com/articulo.asp?id=1098 > . [Consulta: 26/09/2012].

(NAOTTVP) LOZANO SÁNCHEZ, F. S. (2012): «Nuevos anticoagulantes orales en el tratamiento de la trombosis venosa profunda», Angiología, 64, 5, 212-7:

<http://www.elsevier.es/sites/default/files/elsevier/eop/S00033170\%2812\%29000 75-2.pdf>. [Consulta: 28/09/2012].

(NCMPAC) MYERS, M. G., L. RUILOPE (2012): «Nuevas consideraciones sobre la medida de la presión arterial en consulta» [Resumen], Hipertensión y Riesgo Vascular, 29, 3, 63-68:

<http://www.elsevier.es/es/revistas/hipertension--riesgo-vascular-67/nuevasconsideraciones-medida-presion-arterial-consulta-90154602-originales-2012>. [Consulta: 28/09/2012].

(NDVA) BARBA, Ignasi, Eduardo VillaCORTA et al. (2012): «Nanopartículas derivadas de válvula aórtica: sin evidencias de vida», Revista Española de Cardiología, 65,9, 813-818:

$<$ http://www.elsevier.es/es/revistas/revista-espa\%C3\%B1ola-cardiologia25/nanoparticulas-derivadas-valvula-aortica-evidencias-vida-90150854-investigacionbasica-2012>.

(OTTAPC) ZARAGOZA, Rafael y Javier PEMÁN (2012): «Opciones terapéuticas para el tratamiento antifúngico en el paciente crítico», Revista Iberoamericana de Micología, 29,2, 108-113:

<http://www.reviberoammicol.com/2012-29/108113.pdf $>$ [Consulta: 26/09/2012].

(PBPP) HARRIS RiCARDO, Joanthan, Martha REBOlLEDO COBOS et al. (2012): «Papiloma bucal en pacientes Pediátricos: Potencial transmisión materna», Revista Clínica 
de Medicina de Familia, 5, 1, 46-50:

<http://scielo.isciii.es/pdf/albacete/v5n1/paciente1.pdf >. [Consulta: 28/09/2012].

(PCTPT) CATAlina Romero, Carlos, Juan Carlos SAInz GutiÉRrez et al. (2012): «Prevalencia de consumo de tabaco en población trabajadora tras la entrada en vigor de la ley 42/2010», Revista Española de Salud Pública, 86, 2, 178-188:

<http://scielo.isciii.es/pdf/resp/v86n2/06_original5.pdf > . [Consulta: 26/09/2012].

(PGEAP) Alvite CANosa, Marlén, Inmaculada Monjero Ares et al. (2012): «Pioderma gangrenoso con extensa afectación perianal», Revista Española de Enfermedades Digestivas, 104, 2, 92-93:

$<$ http://scielo.isciii.es/scielo.php?pid=S1130-

01082012000200009\&script=sci_arttext\&tlng=es>. [Consulta: 28/09/2012].

(PPSSTE) GUIRAO, X, A. CISCAR et al. (2012): «Peritonitis primaria y síndrome del shock tóxico estreptocócico», Casos Clínicos de Cirugía General, 4,1, 2-7:

$<$ http://www.aecirujanos.es/revista_cirugia_casos_clinicos/revista_casos_clinicos _cirugia_general_N7.pdf $>$. [Consulta: 28/09/2012].

(PREEC) Mora-VAlverde, José Alberto (2012): «Preeclampsia», Revista Médica de Costa Rica y Centroamérica, LXIX, 602, 193-198:

〈http://www.binasss.sa.cr/revistas/rmcc/602/art6.pdf > . [Consulta: 26/09/2012].

(PRMFCPFE) LuCAS PÉREZ-Romero, Francisco Javier, Patricia Chacón CASO et al. (2012): «Percepción de los Residentes de Medicina Familiar y Comunitaria sobre el programa formativo de la Especialidad», Revista Clínica de Medicina de Familia, 5,1, 17-24:

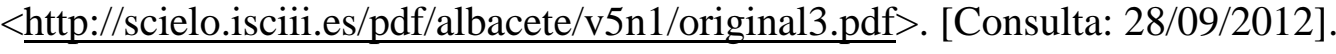

( (2012): «¿Qué indicadores son considerados por enfermería para conseguir una diálisis perfecta en el paciente en hemodiafiltración en línea?», Enfermería Nefrológica, 15, 2, 115-120:

$<$ http://scielo.isciii.es/scielo.php?pid=S225428842012000200006\&script=sci_artt ext $>$. [Consulta: 28/09/2012].

(RCEHO) RodRigo Royo, M. D. et al. (2012): «Razones clínicas de elección de hidromorfona OROS ${ }^{\circledR}$ para el tratamiento de pacientes con dolor crónico no oncológico. Estudio HIDOCO», Revista de la Sociedad Española del Dolor, 19, 3, 125-133:

$<$ http://scielo.isciii.es/scielo.php?pid=S1134-

80462012000300003\&script=sci_arttext $>$. [Consulta: 28/09/2012].

NORMAS. REVISTA DE ESTUDIOS LINGÜÍSTICOS HISPÁNICOS, NÚMERO 2 (AÑO 2012):

http://www.uv.es/normas 
(RIMEPSED) ENRÍQUEZ SÁNCHEZ, S., J. R. DOMÍNGUEZ ViCENT et al. (2012): «Rotura intraabdominal multivisceral espontánea en un paciente con síndrome de EhlersDanlos tipo IV (gen COL3A1) con mutación no descrita», Casos Clínicos de Cirugía General, 4, 1, 8-10:

<http://www.aecirujanos.es/revista_cirugia_casos_clinicos/revista_casos_clinicos _cirugia_general_N7.pdf $>$. [Consulta: 28/09/2012].

$(R M N D)$ VACCARO, C., V. WeInBAUR et al. (2012): «Resonancia magnética nuclear con difusión: una nueva alternativa para valorar la respuesta patológica a la neoadyuvancia por cáncer de recto», Revista Argentina de Cirugía, 100, 1-2, 48-52:

$<$ http://www.scielo.org.ar/scielo.php?script=sci_arttext\&pid=S2250639X2011000 200005\&lng=pt\&nrm=iso $>$. [Consulta: 28/09/2012].

(RPIDPHF) Blasco CABAÑas, Concepción, Ester Ponz Clemente et al. (2012): «Relación entre la presión intraabdominal en diálisis peritoneal con las hernias y fugas», Enfermería Nefrológica, 15, 2, 94-100:

<http://scielo.isciii.es/pdf/enefro/v15n2/original2.pdf>. [Consulta: 28/09/2012].

(RRQAI) HERNANDO RYDINGS, M., I. MARÍNEZ LÓPEZ et al. (2012): «Resultados de la reparación quirúrgica de los aneurismas inflamatorios de aorta abdominal: evolución de los reactantes de fase aguda y de la reacción inflamatoria periaórtica», Angiología, 64, 5, 206-211:

<http://scielo.isciii.es/pdf/enefro/v15n2/original2.pdf>. [Consulta: 28/09/2012].

(SCEUCTFA) Álvarez GARCÍA, J. et al. (2012): «Serie de casos. Experiencia de un único centro en el tratamiento de fístulas aortoentéricas» [Resumen], Angiología, 64(5), 199-205:

$<$ http://www.elsevier.es/es/abstract/revistas/angiologia-294/serie-casosexperiencia-un-unico-centro-tratamiento-90153657-originales-2012?bd=1>. [Consulta: 28/09/2012].

(SPUD) PÉRez Domínguez, Tais, Armando Rodríguez PÉRez et al. (2012): «Satisfacción del paciente en una Unidad de Diálisis. ¿Qué factores modulan la satisfacción del paciente en diálisis?», Enfermería Nefrológica, 15, 2, 101-107:

$<$ http://scielo.isciii.es/scielo.php?pid=S2254-

28842012000200004\&script=sci_arttext>. [Consulta: 28/09/2012].

(TCCI) EsCobedo URIBE, Carlos David, Adriana Elixabeth MonsiváIs URENDA et al. (2012): «La terapia celular en la cardiopatía isquémica», Archivos de Cardiología de México, 82, 3, 218-229: 
<http://www.archivoscardiologia.org.mx/historico/VOL.\%2082\%20A\%D10\%20 82\%20(2012)/NUMERO\%203/11-6.pdf> . [Consulta: 26/09/2012].

(TEBD) ANDiCOECHEA AgORRÍA, Alejandro et al. (2012): «Tratamiento endoscópico con balón de dilatación combinado con inyección intralesional de corticoides en las estenosis de anastomosis colorrectales refractarias a la dilatación simple», Cirugía Española, 90, 5, 329-342:

$<$ http://www.elsevier.es/es/revistas/cirugia-espa\%C3\%B1ola-36/tratamientoendoscopico-balon-dilatacion-combinado-inyeccion-intralesional-90135020-cartascientificas-2012>. [Consulta: 01/10/2012].

(TGIST) Rico ARrastiA, Aida, P. SÁNCHEZ ACEDO et al. (2012): «Tumores GIST: presentación de dos casos como urgencia quirúrgica», Casos Clínicos de Cirugía General, 4, 1, 21-24:

$<$ http://www.aecirujanos.es/revista_cirugia_casos_clinicos/revista_casos_clinicos _cirugia_general_N7.pdf >. [Consulta: 28/09/2012].

(UCMCC) BERTY TEJEDAS, J. et al. (2012): «Utilidad del campo magnético en la cervicobraquialgia crónica», Revista de la Sociedad Española del Dolor, 19, 3, 117 134:

$<$ http://scielo.isciii.es/scielo.php?pid=S113480462012000300002\&script=sci_artt ext>. [Consulta: 28/09/2012].

(UDEA) LÓPEZ GONZÁLEZ, Antonio et al. (2012): «La unidad de diálisis, ¿un entorno accesible?», Enfermería Nefrológica, 15, 2, 121-127:

$<$ http://scielo.isciii.es/scielo.php?pid=S225428842012000200007\&script=sci_arttext>. [Consulta: 28/09/2012].

(UPC8) TRINIDAD, J. M. y L. M. TORRES (2012): «Uso del parche de capsaicina $8 \%$ para el tratamiento del dolor por infusión de trepostinil subcutáneo», Revista de la Sociedad Española del Dolor, 19, 3, 134-137:

$<$ http://scielo.isciii.es/scielo.php?pid=S1134-

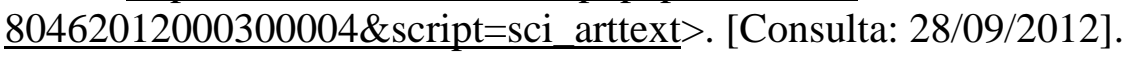

(UVIFICB) DiP, F., L. Alle, M. Nahmod et al. (2011): «Utilización de verde de indocianina fluorescente intraoperatorio en cirugía biliar. Factibilidad del método: experiencia inicial», Revista Argentina de Cirugía, 100, 1-2, 19-22:

<http://www.scielo.org.ar/pdf/racir/v100/v100a03.pdf >. [Consulta: 28/09/2012].

(VB) Trejos Valverde, Ronny (2012): «Vaginosis bacteriana», Revista Médica de Costa Rica y Centroamérica, LXIX, 602, 183-187:

〈http://www.binasss.sa.cr/revistas/rmcc/602/art4.pdf > . [Consulta: 01/10/2012]. 
(VINIP) PÉREZ Agustí, Adolfo (2012): «Vacunación infantil. ¿Necesaria, ineficaz o peligrosa?», Revista Natural (en línea):

<http://www.revistanatural.com/articulo.asp?id=1096>. [Consulta: 26/09/2012].

(VMNOPA) SEgrelles CAlvo, Gonzalo, Enrique ZAMORA GARCía et al. (2012): «Ventilación mecánica no invasiva en una población anciana que ingresa en una unidad de monotorización respiratoria: causas, complicaciones y evolución al año de seguimiento», Archivos de Bronconeumología, 48, 10, 349-354:

<http://www.sciencedirect.com/science/article/pii/S0300289612001871>. [Consulta: $28 / 09 / 2012]$.

(VNRAVGPe) Algualcil Ramos, Ana María, José Antonio Lluch Rodrigo et al. (2012): «Variabilidad en la notificación de reacciones adversas a las vacunas de la gripe pandémica y estacional. Temporadas 2009-2010 y 2010-2011, Comunitat Valenciana», Revista Española de Salud Pública, 86, 3, 241-251:

$<$ http://www.msc.es/biblioPublic/publicaciones/recursos_propios/resp/revista_cdr om/vol86/vol86_3/RS863C_241.pdf>. [Consulta: 26/09/2012]. 
